\title{
New Optimized Network Selection Decision In Heterogeneous Wireless Networks
}

\author{
Mohamed Lahby, Leghris Cherkaoui, Abdellah Adib \\ Department of Computer Science, LIM Lab. \\ Faculty of Sciences and Technology of Mohammedia B.P. 146 Mohammedia, Morocco
}

\begin{abstract}
The expected growth in radio access technologies (RAT's) such as wireless technologies (802.11a, 802.11b, 802.15, 802.16, etc.) and cellular networks (GPRS, UMTS, HSDPA, LTE, etc.) requires efficient vertical handoff algorithm. Variety of vertical handoff algorithms (VHA) have been proposed to help the user to select dynamically the best access network (BAN) in terms of quality of service. The objective of this paper is to provide an optimized network selection decision that allow mobile users to choose the BAN with seamless manner and to exploit a minimum of criteria for all traffic classes namely: background conversational, interactive and streaming. Our optimized algorithm combines two multi attribute decision making (MADM) methods such as analytic network process (ANP) method to weigh the criteria, and the novel method based on mahalanobis distance (NMMD) to rank the alternatives.
\end{abstract}

\section{Keywords:}

Heterogeneous Wireless Networks, Network Selection, IEEE 802.21, Multi Attribute Decision Making, Criticality Analysis

\section{INTRODUCTION}

With the expected growth in radio access technologies (RAT's) such as wireless technologies (802.11a, 802.11b, 802.15, 802.16, etc.) and cellular networks (GPRS, UMTS, HSDPA, LTE, etc.) two issues are involved. The first issue is how to ensure ubiquitous access for the end users, under the principle "Always Best Connected" (ABC) [1] and the second issue is how to select the most suitable network in terms of quality of service. To deal with these issues the network selection decision [2] is intended to keep the connection when the terminal mobile transfers call from one base station (BS) or point of attachment (AP) which is based on one of RAT's to another base station which based on different RAT's.

The network selection problem is heterogeneous wireless networks is complex problem mapped in NP-Hard problem [3], hence it is desirable to use a heuristic algorithm in order to achieve an optimal network selection which can satisfy better trade-off between network conditions, requirements of applications and users preferences.

The network selection depends on multiple handover metrics, from terminal side: battery, velocity, life user preferences, and from the network side: provider's profile, current QoS parameters.

Three issues dominate the network selection which are a) selecting the appropriate handover metrics, b) identification the most algorithm that exploits these metrics and c) determination the appropriate weighting algorithms that allow to weigh each criterion for each traffic classes.

The rest of this paper is organized as follows. Section 2 presents review of related work concerning these three issues. Section 3 describes Multi Attribute Decision Making methods (MADM). Section 4 presents our optimized network selection algorithm. In section 5, nmerical result and discussion are provided to show the effectiveness of the optimized network selection algorithm. Section 6 concludes this paper.

\section{RELATED WORK}

Several decision algorithms based on multi attribute decision making (MADM) have been proposed and developed exhaustively in the literature to solve the network selection problem. The MADM includes many methods such as analytic hierarchy process (AHP), simple additive weighting (SAW), multiplicative exponential weighting (MEW), grey relational analysis (GRA), and technique for order preference by similarity to ideal solution (TOPSIS). In [4], [5], [6], and [7] the network selection algorithm is based on Analytic Hierarchy Process (AHP) and Gray Relation Analysis (GRA) two MADM methods. The AHP method is used to determine weights for each criterion and GRA method is applied to rank the alternatives. In [8], [9] and [10], the network selection algorithm combines two MADM methods AHP and TOPSIS. The AHP method is used to get weights of the criteria and TOPSIS method is applied to determine the ranking of access network.

In addition, there are several methods used to assign weights for the criteria such as as analytic hierarchy process (AHP), fuzzy analytic hierarchy process (FAHP), analytic network process (ANP), fuzzy analytic network process (FANP) and random weighting. Determining the most suitable weights for different criteria for each traffic classes is one of the main problems in the network selection decision. In [11] five weighting algorithms namely AHP, FAHP, ANP, FANP and RW are studied and compared for all four traffic classes namely,conversational, streaming, interactive and background.

In addition due to the variety of vertical handoff algorithms (VHA) some evaluation models for VHA have proposed in the literature, in [12] the authors compare the performance of five VHA, namely SAW, MEW, TOPSIS, GRA, and UA (Abique's Algoritm). Each VHA method used the AHP method to get weights of the criteria and the fuzzy logic is applied to build the evaluation scale and compare different handover metrics. Two traffic classes were considered conversational and streaming. Each traffic class was associated with six handover metrics namely available bandwidth, bit error rate, delay, security and monetary costs.

In [13], the authors proposed a multi-constraint optimization technique in order to achieve better tradeoff between set of handover metrics such as bit error rate (BER), available bandwidth $(\mathrm{ABW})$ and network traffic (NT). The proposed algorithm is based on the results of performance evaluation parameters 
namely handoff dropping and call blocking probability. In addition the sensitivity analysis for four traffic classes are presented as follows: the background traffic is sensitive to the ABW, the interactive traffic is sensitive to BER, the conversational traffic and the streaming traffic are sensitive to the NW.

In [14], the author compare the performance of seven VHA based on MADM methods which are SAW, MEW, TOPSIS, ELECTRE, VIKOR, GRA and WMC (weighted markov chain). The performance evaluation is focused on four parameters of QoS namely packet delay, packet jitter, the available bandwidth and the total bandwidth. Two different applications were considered: voice and data connections. Each traffic application was associated with six attributes: available bandwidth, total bandwidth, packet delay, packet jitter, packet loss and cost per byte.

In [15] and [16] the authors have proposed a new evaluation model for VHA based on multi criteria evaluation and criticality analysis. In one hand the proposed model in [15] allows to evaluate the performance of VHA methods by using the measured values of three parameters namely number of handoffs, handoff delay and computational complexity. In the other hand the proposed evaluation model in [16] is used to evaluate the performance of five MADM methods namely SAW, MEW, TOPSIS, ELECTRE, and VIKOR. For each MADM method we analyze the performance of five parameters namely available bandwidth, delay, jitter, packet loss and cost ber byte. However, one of the major limitations of this model is the lack of a weighting algorithm which can be used to assign a relative weight to each handover metric by considering each traffic classes. To address this issue, in [17] the authors have proposed an enhanced evaluation model based on MADM methods and criticality analysis. The enhanced evaluation model is used to evaluate three vertical handover algorithms based on MADM methods namely TOPSIS, GRA and DIA. According to the simulation results, the GRA method is most appropriate network selection algorithm for all traffic classes namely: background, conversational, interactive and streaming.

In [18], the authors present some researches that have been published concerning the requirements of vertical handover algorithms in heterogeneous wireless networks. The requirements represent the performance metrics which should be used in the network selection decision and which can influence directly the performance of the vertical handover decision. The requirements include ten parameters such as bandwidth, handoff latency, power consumption, network cost, user preferences, network throughput, network load balancing, network security received signal strength and velocity. According of this work, there is no vertical handoff algorithm that satisfies all the requirements, although all vertical handoff algorithms satisfy at least five performance metrics.

However, one of the major weakness of this survey work is that the evaluation of which criteria should be used is not being done on the basis of performance of the algorithms which exploit these criteria. In addition we have three other weaknesses related to all vertical handoff algorithms. The first weakness is related to all vertical handoff algorithms which use the same criteria for each traffic classes, however the metrics should be determined bu the service offered by the network. For example to deliver streaming traffic, the identification of criteria based QoS must not only satisfy streaming traffic in terms of reduced end to end delay but must also takes into consideration low bit error rate which is not necessary to deliver background traffic. In a second hand, the weakness is about the majority of the vertical handoff algorithms which introduce redundant criterion due to correlation between theme. The use of unique selection of handover metrics is very important to reduce the computation time in the terminal during the execution of the vertical handover algorithm, therefore, this will minimize the handover latency. The last weakness consider that there is no performance evaluation models which can be used to identify the most appropriate criteria which should be taken into consideration for the vertical handover mechanism. To cope with these weaknesses, this paper proposes an optimized network selection algorithm which contains two components. The first component is an efficient vertical handoff algorithm which is used to select the best access network. The second component is the enhancement of the evaluation model proposed in [18] which is applied to identify the criteria based QoS which should be used in the vertical handover algorithm.

\section{MULTI ATTRIBUTE DECISION MAKING}

\subsection{ANP}

The Analytic network Process (ANP) is a MADM method, proposed by Saaty [19], which extends the AHP approach to problems with dependence and feed beck within clusters (inner dependence) and between clusters (outer dependence).

The ANP approach is based on six steps:

(1) Model construction: A problem is decomposed into a network in which nodes corresponds to components. The elements in a component can interact with some or all of the elements of another component. Also, relationships among elements in the same component can exist. These relationships are represented by arcs with directions.

(2) Construct of the pairwise comparisons: To establish a decision, ANP builds the pairwise matrix comparison such as

$$
A=\left(\begin{array}{ccccc}
x_{11} & x_{12} & \ldots & \ldots & x_{1 n} \\
x_{21} & x_{22} & \ldots & \ldots & x_{2 n} \\
\vdots & \vdots & \vdots & \ddots & \vdots \\
x_{n 1} & x_{n 2} & \ldots & \ldots & x_{n n}
\end{array}\right) \text { where } x_{j i}= \begin{cases}1 & \text { if } i=j ; \\
\frac{1}{x_{i j}} & \text { if } i \# j .\end{cases}
$$

Elements $x_{i j}$ are obtained from the table 1, it contains 1-9 preference scales.

Table 1. Saaty's scale for pairwise comparison

\begin{tabular}{|c|c|}
\hline Saaty's scale & The relative importance of the two sub-elements \\
\hline \hline 1 & Equally important \\
3 & Moderately important with one over another \\
5 & Strongly important \\
7 & Very strongly important \\
9 & Extremely important \\
$2,4,6,8$ & Intermediate values \\
\hline
\end{tabular}

(3) Construct the normalized decision matrix: $A_{\text {norm }}$ is the normalized matrix of $\mathrm{A}(1)$, where $A\left(x_{i j}\right)$ is given by, $A_{\text {norm }}\left(a_{i j}\right)$ such:

$$
a_{i j}=\frac{x_{i j}}{\sum_{i=1}^{n} x_{i j}}
$$

(4) Calculating the weights of criterion: The weights of the decision factor i can be calculated by

$$
W_{i}=\frac{\sum_{j=1}^{n} a_{i j}}{n} \text { and } \sum_{j=1}^{n} W_{i}=1
$$

With $\mathrm{n}$ is the number of the compared elements.

(5) Calculating the coherence ratio (CR): To test consistency of a pairwise comparison, a consistency ratio (CR) can be introduced with consistency index (CI) and random index (RI).

Let define consistency index CI

$$
C I=\frac{\lambda_{\max }-n}{n-1}
$$


Table 2. Value of random consistency index RI

\begin{tabular}{|c|c|c|c|c|c|c|c|c|}
\hline criteria & $\mathbf{3}$ & $\mathbf{4}$ & $\mathbf{5}$ & $\mathbf{6}$ & $\mathbf{7}$ & $\mathbf{8}$ & $\mathbf{9}$ & $\mathbf{1 0}$ \\
\hline RI & 0.58 & 0.90 & 1.12 & 1.24 & 1.32 & 1.41 & 1.45 & 1.49 \\
\hline
\end{tabular}

Also, we need to calculate the $\lambda_{\max }$ by the following formula:

$$
\lambda_{\max }=\frac{\sum_{i=1}^{n} b_{i}}{n} \text { such } b_{i}=\frac{\sum_{j=1}^{n} W_{i} * a_{i j}}{W_{i}}
$$

We calculate the coherence ratio $\mathrm{CR}$ by the following formula:

$$
C R=\frac{C I}{R I}
$$

The various values of RI are shown in table 2 . If the CR is less than 0.1, the pairwise comparison is considered acceptable.

(6) Construct the super-matrix formation: The local priority vectors are entered into the appropriate columns of a supermatrix, which is a partitioned matrix where each segment represents a relationship between two components.

\subsection{Novel Method based on Mahalanobis Distance}

The novel method based on mahalanobis distance (NMMD), algorithm belonging to the MADM category, that we developed [20] to select dynamically the best network interface. This algorithm is based on mahalanobis distance which takes into account the correlation between variables by which different patterns can be identified and analyzed. The mahalanobis distance between an individual $\mathrm{x}$ and a population's multivariate mean $\mathrm{u}$ is computed by:

$$
D_{M}(x)=(x-u)^{T} * S^{-1} *(x-u)
$$

Where $S^{-1}$ is the inverse covariance matrix

The NMMD based network selection consists of the following steps:

(1) Construct of the decision matrix: the decision matrix is expressed as

$$
D=\left(\begin{array}{ccccc}
d_{11} & d_{12} & \ldots & \ldots & d_{1 n} \\
d_{21} & d_{22} & \ldots & \ldots & d_{2 n} \\
\vdots & \vdots & \vdots & \ddots & \vdots \\
d_{n 1} & d_{n 2} & \ldots & \ldots & d_{n n}
\end{array}\right)
$$

Where $d_{i j}$ is the rating of the alternative $A_{i}$ with respect to the criterion $C_{j}$

(2) Construct the normalized decision matrix: each element $r_{i j}$ is obtained by Max method normalization.

-For benefit attribute, the normalized value of $r_{i j}$ is computed as:

$$
r_{i j}=\frac{d_{i j}}{d_{j}^{\text {max }}}
$$

where $d_{j}^{\max }$ is the maximum performance rating among alternatives for attribute $C_{j}(\mathrm{j}=1, \ldots, \mathrm{m})$, and $d_{i j}$ is the actual parameter value of a given network.

-For cost attribute, the normalized value of $r_{i j}$ is computed as:

$$
r_{i j}=\frac{d_{j}^{\text {min }}}{d_{i j}}
$$

where $d_{j}^{\text {min }}$ is the minimum performance rating among alternatives for attribute $C_{j}(\mathrm{j}=1, \ldots, \mathrm{m})$, and $d_{i j}$ is the actual parameter value of a given network.
(3) Construct the weighted normalized decision matrix: The weighted normalized decision matrix $v_{i j}$ is computed as:

$$
v_{i j}=W_{i} * r_{i j} \text { where } \sum_{i=1}^{m} W_{i}=1
$$

(4) Calculate the mahalanobis distance of each $A_{i}$ : can be calculated as equation 6 , the result as expressed by:

$$
D_{M}\left(A_{i}\right)=\left[D_{i 1}, \ldots, D_{i m}\right]
$$

(5) Calculate the mean of the attributes vector obtained as equation 11.

$$
C_{i}=\frac{\sum_{j=1}^{m} D_{i j}}{m}
$$

(6) Select the best access network: A set of alternative can now ranked according the increasing order of $C_{i}$.

\section{OPTIMIZED NETWORK SELECTION ALGORITHM}

In order to identify the suitable QoS parameters which should be used for vertical handover algorithm, we proposes an optimized network selection algorithm. This one has two components listed below: the first component is an efficient vertical handoff algorithm and the second component is the enhancement of the evaluation model for VHA.

\subsection{The Proposed Vertical Handover Algorithm}

The vertical handover algorithm combines two MADM methods such as ANP and NMMD. The algorithm assumes wireless overlay networks which entails three heterogeneous networks such as UMTS, WLAN and WIMAX. The six parameters associated to the three networks are: Cost per Byte (CB), Security (S), Available Bandwidth (AB), Packet Delay (D), Packet Jitter (J) and Packet Loss (L). In the one hand, IEEE 802.21 framework [21] is used in order to collect the QoS parameters such as AB, D, $\mathrm{J}$, and $\mathrm{L}$ of the available networks. However, IEEE 802.21 is well known as Media Independent Handover, which designed to support seamless handover among heterogeneous wireless networks. Fig. 1 exhibits the three levels ANP hierarchy for network selection problem. The level 1 includes three criteria QoS, security and cost, the level 2 includes four QoS parameters such as $\mathrm{AB}, \mathrm{D}, \mathrm{J}$ and $\mathrm{L}$ and the level 3 includes three available networks UTMS, WIFI and WIMAX.

Our vertical handover algorithm consists of the four following steps:

(1) Assign weights to level-1: the ANP method is used to get a weight of the decision criteria of level 1.

(2) Assign weights to level-2: the ANP method is used to get a weight of the decision criteria of level 2.

(3) Assign weights to level-3: the weight vector of each available network is calculated by multiplication of the weight vector obtained in level 1 with the weight vector obtained in level 2.

(4) Select the best access network: the method NMMD is applied to rank the the available networks and select the access network that has the highest value of $C_{j}^{*}$ (see the steps of NMMD method).

\subsection{The Enhancement of The Evaluation Model}

In this section, we present an enhancement of the evaluation model [17] which combines the multi criteria evaluation and criticality analysis. This model allows to identify the QoS parameters which should be used in our vertical handover algorithm according to background traffic. The procedure can be categorized in seven steps: 


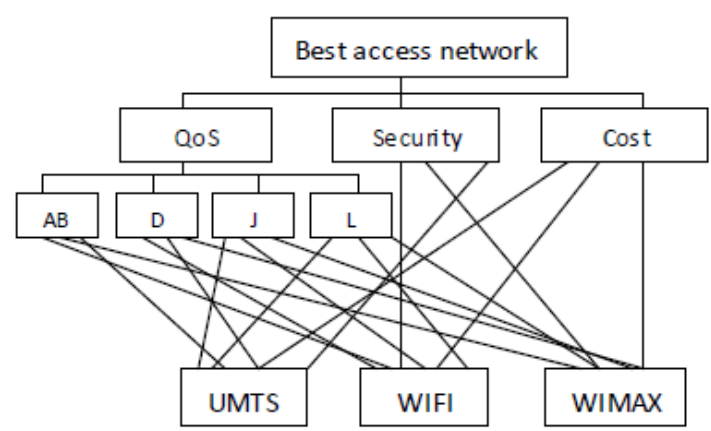

Fig. 1. The three level ANP hierarchy for network selection problem

(1) Identification of the evaluation parameters: the evaluation parameters represent the indicators that influence the performance of vertical handover algorithm and allow to compare between theme. In this study we use two evaluation parameters namely ranking abnormality and number of hanoffs The ranking abnormality means that the ranking of candidate networks change when low ranking alternatives are removed from the candidate list, which can make the hanover vertical algorithm inefficient. The number of handoffs represents the number of network handoffs that the terminal mobile have performed for a given time period.

(2) Construct the evaluation matrix: the evaluation matrix is the decision matrix that represents the evaluation of each vertical hanover algorithm $A l g_{i}$ with respect to the evaluation parameter $P_{j}$. The evaluation matrix is expressed as:

$$
E M=\left(\begin{array}{ccccc}
v_{11} & v_{12} & \ldots & \ldots & v_{1 m} \\
v_{21} & v_{22} & \ldots & \ldots & v_{2 m} \\
\vdots & \vdots & \vdots & \ddots & \vdots \\
v_{n 1} & v_{n 2} & \ldots & \ldots & v_{n m}
\end{array}\right)
$$

Where $v_{i j}$ is the measured value of the vertical handover algorithm $A l g_{i}$ with respect to the evaluation parameter $P_{j}$. The $v_{i j}$ is obtained from simulating vertical handover algorithm by using MATLAB.

(3) Construct the normalized evaluation matrix: in order to control the magnitude of evaluation parameters and to prevent that some of the evaluation parameters can dominate others, we calculate the normalized evaluation matrix by Max method normalization. Each element $d_{i j}$ is computed as equation 8 and 9 .

(4) Construct the criticality matrix: according to valuation scale defined in table 3 , we analyse the evaluation matrix obtained in second step. the criticality matrix $c_{i j}$ is computed as:

$$
c_{i j}=k
$$

Where $\mathrm{k}$ is obtained from table 3 according to the value of $d_{i j}$

(5) Construct the weighted criticality matrix: we apply the ANP method to weigh each evaluation parameter, the weighted criticality matrix $t_{i j}$ is computed as:

$$
t_{i j}=w_{i} * c_{i j} \text { where } \sum_{i=1}^{m} w_{i}=1
$$

(6) Calculation of the criticality index: the criticality index of each vertical handover algorithm $A l g_{i}$ can be calculated as:

$$
C I_{i}=100 *\left(\sum_{j=1}^{m} t_{i j}\right) / n \text { where } i=1, \ldots, n
$$

$\mathrm{n}$ is the maximum valuation level of all parameters.

(7) Ranking: A set of vertical handover algorithms can be ranked according to the decreasing order of $C I_{i}^{*}$.

Table 3. CRITICALITY MATRIX FOR EVALUATING VHA

\begin{tabular}{|c|l|c|c|c|}
\hline $\begin{array}{c}\text { Very low } \\
\mathbf{k = 1}\end{array}$ & $\begin{array}{l}\text { Low } \\
\mathbf{k = 3}\end{array}$ & $\begin{array}{c}\text { Medium } \\
\mathbf{k = 5}\end{array}$ & $\begin{array}{c}\text { High } \\
\mathbf{k = 7}\end{array}$ & $\begin{array}{c}\text { Very hight } \\
\mathbf{k = 9}\end{array}$ \\
\hline $\begin{array}{c}d_{i j}>80 \% \\
\text { of the max } \\
\text { value }\end{array}$ & $\begin{array}{c}d_{i j}>60 \% \\
\text { of the max } \\
\text { value }\end{array}$ & $\begin{array}{c}d_{i j}>40 \% \\
\text { of the max } \\
\text { value }\end{array}$ & $\begin{array}{c}d_{i j}>20 \% \\
\text { of the max } \\
\text { value }\end{array}$ & $\begin{array}{c}d_{i j}<=20 \% \\
\text { of the max } \\
\text { value }\end{array}$ \\
\hline
\end{tabular}

\section{NUMERICAL RESULT AND DISCUSSION}

In this section we show the effectiveness of our enhancement evaluation model in reducing of number of criteria that requires for vertical handover algorithm, we propose the results of study case which based on two steps. The first step we present the performance results of three algorithms namely:

-Alg1: for this algorithm, the vertical handover algorithm is based on ANP and NMMD, the criteria used in this algorithm are cost per byte, available bandwidth, security, packet delay.

- $\mathrm{Alg} 2$ : for this algorithm, the vertical handover algorithm is based on ANP and NMMD, the criteria used in this algorithm are cost per byte, available bandwidth, security, packet delay and packet loss.

— Alg3: for this algorithm, the vertical handover algorithm is based on ANP and NMMD, the criteria used in this algorithm are cost per byte, available bandwidth, security, packet delay, packet jitter and packet loss.

We perform four simulations for four traffic classes [22] namely background, conversational, interactive and streaming by using MATLAB in order to select the suitable vertical handover which should be used. The three algorithms were run in 100 vertical handoff decision points in order to provide the values for average of two performance evaluation namely ranking abnormality and number of handoffs. During the simulation, the measures of every criterion for candidate networks are randomly varied according to the ranges shown in table 4 .

In The second step, we apply the enhancement of the evaluation model to evaluate and analyze the results of the performance of these algorithms in order to select the best of theme.

Table 4. Attribute value for the candidate networks

\begin{tabular}{|l|l|l|l|l|l|l|}
\hline $\begin{array}{c}\text { criteria } \\
\text { network }\end{array}$ & $\begin{array}{c}\text { CB } \\
(\%)\end{array}$ & $\begin{array}{c}\mathbf{S} \\
(\%)\end{array}$ & $\begin{array}{c}\text { AB } \\
(\text { mbps })\end{array}$ & $\begin{array}{c}\mathbf{D} \\
(m s)\end{array}$ & $\begin{array}{c}\mathbf{J} \\
(m s)\end{array}$ & $\begin{array}{c}\mathbf{L} \\
\left(\text { per } 10^{6}\right)\end{array}$ \\
\hline UMTS & 60 & 70 & $0.1-2$ & $25-50$ & $5-10$ & $20-80$ \\
\hline WLAN & 10 & 50 & $1-11$ & $100-150$ & $10-20$ & $20-80$ \\
\hline WIMAX & 50 & 60 & $1-60$ & $60-100$ & $3-10$ & $20-80$ \\
\hline
\end{tabular}

\subsection{The Simulation 1}

In this simulation, the traffic analyzed is background traffic, table 5 shows the analytical results of three algorithms Alg1, Alg2 and Alg3. For each vertical handover algorithm we provided the values for average of two performance evaluation ranking abnormality and number of handoffs.

Based on the Table 3, we analyze the evaluation matrix obtained in the Table 5. The results of the analysis between the Table 3 and the Table 5 are shown in the Table 6 .

Before evaluating the performance parameters of each algorithm in order to choose the best vertical handover algorithm between themes, we use the ANP method to calculate the weights of ranking abnormality and number of handoffs. Table 7 presents the 
Table 5. Measures for ranking abnormality and number of handoffs

\begin{tabular}{|l|l|l|}
\hline $\begin{array}{c}\text { MADM } \\
\text { Algorithms }\end{array}$ & $\begin{array}{c}\text { Ranking abnormality } \\
(\%)\end{array}$ & $\begin{array}{c}\text { Number of handoffs } \\
(\%)\end{array}$ \\
\hline Alg1 & 16 & 40 \\
\hline Alg2 & 21 & 48 \\
\hline Alg3 & 33 & 52 \\
\hline
\end{tabular}

Table 6. The criticality matrix

\begin{tabular}{|l|l|l|}
\hline $\begin{array}{c}\text { MADM } \\
\text { Algorithms }\end{array}$ & Ranking abnormality & Number of handoffs \\
\hline Alg1 & 5 & 3 \\
\hline Alg2 & 3 & 1 \\
\hline Alg3 & 1 & 1 \\
\hline
\end{tabular}

Table 7. Comparison matrix and weighting vector of background traffic

\begin{tabular}{|c|l|l|l|}
\hline $\begin{array}{c}\text { Evaluation } \\
\text { Parameters }\end{array}$ & $\begin{array}{c}\text { Ranking } \\
\text { abnormality }\end{array}$ & $\begin{array}{c}\text { Number } \\
\text { of handoffs }\end{array}$ & Weights \\
\hline $\begin{array}{c}\text { Ranking } \\
\text { abnormality }\end{array}$ & 1 & 1 & 0.5 \\
\hline $\begin{array}{c}\text { Number } \\
\text { of handoffs }\end{array}$ & 1 & 1 & 0.5 \\
\hline
\end{tabular}

associated weights of each performance parameters for background traffic.

Table 8 shows the scores and the criticality index of the all algorithms analyzed for background traffic. We notice that Alg1 has the highest score, which means that this algorithms has the best performance than Alg2 and Alg3.

So for background traffic, it is desirable to use Alg1 algorithm in order to select the best access network, we notice that this algorithm exploits only four criteria namely cost per byte, available bandwidth, security, packet delay.

Table 8. Evaluation of VHA for background traffic

\begin{tabular}{|l|l|l|c|}
\hline $\begin{array}{c}\text { MADM } \\
\text { Algorithms }\end{array}$ & $\begin{array}{c}\text { Ranking } \\
\text { abnormality }\end{array}$ & $\begin{array}{c}\text { Number } \\
\text { of handoffs }\end{array}$ & $\begin{array}{c}\text { Criticality } \\
\text { index }\end{array}$ \\
\hline Alg1 & 5 & 3 & 57.14 \\
\hline Alg2 & 3 & 1 & 28.57 \\
\hline Alg3 & 1 & 1 & 14.29 \\
\hline
\end{tabular}

\subsection{The Simulation 2}

In this simulation, the traffic analyzed is conversational traffic, table 9 shows the analytical results of three algorithms Alg1, Alg2 and Alg3. For each vertical handover algorithm we provided the values for average of two performance evaluation ranking abnormality and number of handoffs.

Table 9. Measures for ranking abnormality and number of handoffs

\begin{tabular}{|l|l|l|}
\hline $\begin{array}{c}\text { MADM } \\
\text { Algorithms }\end{array}$ & $\begin{array}{c}\text { Ranking abnormality } \\
(\%)\end{array}$ & $\begin{array}{c}\text { Number of handoffs } \\
(\%)\end{array}$ \\
\hline Alg1 & 14 & 33 \\
\hline Alg2 & 21 & 46 \\
\hline Alg3 & 29 & 52 \\
\hline
\end{tabular}

Based on the Table 3, we analyze the evaluation matrix obtained in the Table 9. The results of the analysis between the Table 3 and the Table 9 are shown in the Table 10.

Before evaluating the performance parameters of each algorithm in order to choose the best vertical handover algorithm between
Table 10. The criticality matrix

\begin{tabular}{|l|l|l|}
\hline $\begin{array}{c}\text { MADM } \\
\text { Algorithms }\end{array}$ & Ranking abnormality & Number of handoffs \\
\hline Alg1 & 5 & 3 \\
\hline Alg2 & 3 & 1 \\
\hline Alg3 & 1 & 1 \\
\hline
\end{tabular}

themes, we use the ANP method to calculate the weights of ranking abnormality and number of handoffs. Table XI presents the associated weights of each performance parameters for conversational traffic.

Table 11. Comparison matrix and weighting vector of conversational traffic

\begin{tabular}{|c|l|l|l|}
\hline $\begin{array}{c}\text { Evaluation } \\
\text { Parameters }\end{array}$ & $\begin{array}{c}\text { Ranking } \\
\text { abnormality }\end{array}$ & $\begin{array}{c}\text { Number } \\
\text { of handoffs }\end{array}$ & Weights \\
\hline $\begin{array}{c}\text { Ranking } \\
\text { abnormality }\end{array}$ & 1 & $1 / 3$ & 0.250 \\
\hline $\begin{array}{c}\text { Number } \\
\text { of handoffs }\end{array}$ & 3 & 1 & 0.750 \\
\hline
\end{tabular}

Table 12 shows the scores and the criticality index of the all algorithms analyzed for conversational traffic. We notice that Alg1 has the highest score, which means that this algorithms has the best performance than $\mathrm{Alg} 2$ and $\mathrm{Alg} 3$.

So for conversational traffic, it is desirable to use Alg1 algorithm in order to select the best access network.

Table 12. Evaluation of VHA for conversational traffic

\begin{tabular}{|l|l|l|l|}
\hline $\begin{array}{c}\text { MADM } \\
\text { Algorithms }\end{array}$ & $\begin{array}{c}\text { Ranking } \\
\text { abnormality }\end{array}$ & $\begin{array}{c}\text { Number } \\
\text { of handoffs }\end{array}$ & $\begin{array}{c}\text { Criticality } \\
\text { index }\end{array}$ \\
\hline Alg1 & 5 & 3 & 70.00 \\
\hline Alg2 & 3 & 1 & 30.00 \\
\hline Alg3 & 1 & 1 & 20.00 \\
\hline
\end{tabular}

\subsection{The Simulation 3}

In this simulation, the traffic analyzed is interactive traffic, table 13 shows the analytical results of three algorithms Alg1, Alg2 and Alg3. For each vertical handover algorithm we provided the values for average of two performance evaluation ranking abnormality and number of handoffs.

Table 13. Measures for ranking abnormality and number of handoffs

\begin{tabular}{|l|l|l|}
\hline $\begin{array}{c}\text { MADM } \\
\text { Algorithms }\end{array}$ & $\begin{array}{c}\text { Ranking abnormality } \\
(\%)\end{array}$ & $\begin{array}{c}\text { Number of handoffs } \\
(\%)\end{array}$ \\
\hline Alg1 & 32 & 60 \\
\hline Alg2 & 28 & 72 \\
\hline Alg3 & 38 & 80 \\
\hline
\end{tabular}

Based on the Table 3, we analyze the evaluation matrix obtained in the Table 13. The results of the analysis between the Table 3 and the Table 13 are shown in the Table 14.

Table 14. The criticality matrix

\begin{tabular}{|l|l|l|}
\hline $\begin{array}{c}\text { MADM } \\
\text { Algorithms }\end{array}$ & Ranking abnormality & Number of handoffs \\
\hline Alg1 & 1 & 3 \\
\hline Alg2 & 3 & 1 \\
\hline Alg3 & 1 & 1 \\
\hline
\end{tabular}


Before evaluating the performance parameters of each algorithm in order to choose the best vertical handover algorithm between themes, we use the ANP method to calculate the weights of ranking abnormality and number of handoffs. Table 15 presents the associated weights of each performance parameters for interactive traffic.

Table 15. Comparison matrix and weighting vector of interactive traffic

\begin{tabular}{|c|l|l|l|}
\hline $\begin{array}{c}\text { Evaluation } \\
\text { Parameters }\end{array}$ & $\begin{array}{c}\text { Ranking } \\
\text { abnormality }\end{array}$ & $\begin{array}{c}\text { Number } \\
\text { of handoffs }\end{array}$ & Weights \\
\hline $\begin{array}{c}\text { Ranking } \\
\text { abnormality }\end{array}$ & 1 & $1 / 5$ & 0.167 \\
\hline $\begin{array}{c}\text { Number } \\
\text { of handoffs }\end{array}$ & 5 & 1 & 0.833 \\
\hline
\end{tabular}

Table 16 shows the scores and the criticality index of the all algorithms analyzed for interactive traffic. We notice that Alg1 has the highest score, which means that this algorithms has the best performance than $\mathrm{Alg} 2$ and $\mathrm{Alg} 3$.

So for interactive traffic, it is desirable to use $\mathrm{Alg} 1$ algorithm in order to select the best access network.

Table 16. Evaluation of VHA for interactive traffic

\begin{tabular}{|l|l|l|c|}
\hline $\begin{array}{c}\text { MADM } \\
\text { Algorithms }\end{array}$ & $\begin{array}{c}\text { Ranking } \\
\text { abnormality }\end{array}$ & $\begin{array}{c}\text { Number } \\
\text { of handoffs }\end{array}$ & $\begin{array}{c}\text { Criticality } \\
\text { index }\end{array}$ \\
\hline Alg1 & 1 & 3 & 53.33 \\
\hline Alg2 & 3 & 1 & 26.66 \\
\hline Alg3 & 1 & 1 & 20.00 \\
\hline
\end{tabular}

\subsection{The Simulation 4}

In this simulation, the traffic analyzed is streaming traffic, table 17 shows the analytical results of three algorithms Alg1, Alg2 and Alg3. For each vertical handover algorithm we provided the values for average of two performance evaluation ranking abnormality and number of handoffs.

Table 17. Measures for ranking abnormality and number of handoffs

\begin{tabular}{|l|l|l|}
\hline $\begin{array}{c}\text { MADM } \\
\text { Algorithms }\end{array}$ & $\begin{array}{c}\text { Ranking abnormality } \\
(\%)\end{array}$ & $\begin{array}{c}\text { Number of handoffs } \\
(\%)\end{array}$ \\
\hline Alg1 & 20 & 35 \\
\hline Alg2 & 26 & 43 \\
\hline Alg3 & 36 & 54 \\
\hline
\end{tabular}

Based on the Table 3, we analyze the evaluation matrix obtained in the Table 17. The results of the analysis between the Table 3 and the Table 17 are shown in the Table 18.

Table 18. The criticality matrix

\begin{tabular}{|l|l|l|}
\hline $\begin{array}{c}\text { MADM } \\
\text { Algorithms }\end{array}$ & Ranking abnormality & Number of handoffs \\
\hline Alg1 & 5 & 3 \\
\hline Alg2 & 3 & 3 \\
\hline Alg3 & 1 & 1 \\
\hline
\end{tabular}

Before evaluating the performance parameters of each algorithm in order to choose the best vertical handover algorithm between themes, we use the ANP method to calculate the weights of ranking abnormality and number of handoffs. Table 19 presents the associated weights of each performance parameters for streaming traffic.
Table 19. Comparison matrix and weighting vector of streaming traffic

\begin{tabular}{|c|l|l|l|}
\hline $\begin{array}{c}\text { Evaluation } \\
\text { Parameters }\end{array}$ & $\begin{array}{c}\text { Ranking } \\
\text { abnormality }\end{array}$ & $\begin{array}{c}\text { Number } \\
\text { of handoffs }\end{array}$ & Weights \\
\hline $\begin{array}{c}\text { Ranking } \\
\text { abnormality }\end{array}$ & 1 & $1 / 7$ & 0.125 \\
\hline $\begin{array}{c}\text { Number } \\
\text { of handoffs }\end{array}$ & 7 & 1 & 0.875 \\
\hline
\end{tabular}

Table 20 shows the scores and the criticality index of the all algorithms analyzed for streaming traffic. We notice that Alg1 has the highest score, which means that this algorithms has the best performance than Alg2 and Alg3.

So for streaming traffic, it is desirable to use Alg1 algorithm in order to select the best access network.

Table 20. Evaluation of VHA for streaming traffic

\begin{tabular}{|l|l|l|l|}
\hline $\begin{array}{c}\text { MADM } \\
\text { Algorithms }\end{array}$ & $\begin{array}{c}\text { Ranking } \\
\text { abnormality }\end{array}$ & $\begin{array}{c}\text { Number } \\
\text { of handoffs }\end{array}$ & $\begin{array}{c}\text { Criticality } \\
\text { index }\end{array}$ \\
\hline Alg1 & 5 & 3 & 65.00 \\
\hline Alg2 & 3 & 3 & 60.00 \\
\hline Alg3 & 1 & 1 & 20.00 \\
\hline
\end{tabular}

\section{CONCLUSION}

In this work, we have proposed a new optimized network selection algorithm which allows to select the most appropriate criteria which should be used for vertical handover decision. The simulation results show that, our method based on Alg1 can reduce the handover metrics for all traffic classes namely: background conversational, interactive and streaming.

So we deduce that due to correlation between the three criteria packet delay, packet jitter and packet loss our optimized network selection algorithm eliminates packet jitter and packet loss. The reducing of the criteria is very important to minimize the computation time during the execution of the vertical handover.

\section{REFERENCES}

[1] E. Gustafsson and A. Jonsson, "Always best connected", IEEE Wireless Communications Magazine, vol.10, no.1,pp.49-55, Feb. 2003.

[2] H. Wang, R. Katz, J. Giese "Policy-enabled handoffs across heterogeneous wireless networks", Second IEEE Worshop on Mobile Computing systems and Applications, WMCSA. pp. 51-60, February 1999.

[3] Gazis, V.; Houssos, N.; Alonistioti, N.; Merakos, L., "On the complexity of Always Best Connected in $4 G$ mobile networks", Vehicular Technology Conference, VTC IEEE 58th, pp. 2312- 2316 Vol.4, Oct. 2003.

[4] N. Joe, W. Kim, S. Hong, "A Network Selection Algorithm considering Power Consumption in Hybrid Wireless Networks", in Proc. IEEE ICCCN 2007, Honolulu, USA, pp.1240-1243, Aug. 2007.

[5] J. Fu, J. Wu, J. Zhang, L. Ping, and Z. Li, “ Novel AHP and GRA Based Handover Decision Mechanism in Heterogeneous Wireless Networks", in Proc. CICLing (2), pp.213220, 2010.

[6] Wang Yafang; Cui Huimin; Zhang Jinyan. "Network access selection algorithm based on the Analytic Hierarehy Process and Gray Relation Analysis", in Proc. New Trends in Information Science and Service Science NISS'2010, pp.503506, May 2010. 
[7] Husza k, A. Imre, S. "Eliminating Rank Reversal Phenomenon in GRA-Based Network Selection Method ", International Communications Conference (ICC2010) in Cape Town, South Africa, pp.1-6, May 2010.

[8] M. Lahby, C. Leghris. and A. Adib. "A Hybrid Approach for Network Selection in Heterogeneous Multi-Access Environments", In the Proceedings of the 4th IFIP International Conference on New Technologies, Mobility and Security (NTMS), pp.1-5, Paris France, Feb 2011.

[9] A. Sgora, D. Vergados, P. Chatzimisios. "An access network selection algorithm for heterogeneous wireless environments", iscc, pp.890-892, The IEEE symposium on Computers and Communications, 2010.

[10] F. Bari and V. Leung, "Multi-attribute network selection by iterative TOPSIS for heterogeneous wireless access", 4th IEEE Consumer Communications and Networking Conference, pp.808-812, January 2007.

[11] M. Lahby, C. Leghris. and A. Adib. "A Survey and Comparison Study on Weighting Algorithms for Access Network Selection", In the Proceedings of the 9th Annual Conference on Wireless On-Demand Network Systems and Services (WONS) Italy, pp.35-38, January 2012.

[12] I. Lassoued, J. Bonnis, Z. Hamouda and A. Belghith. "A methodology for evaluation vertical handoff decision mech anisms", In Seventh International Conference on Networking (ICN2008), pp.377 - 384, April 2008.

[13] R. Babu, H.S, Sekhar, G.N, Satyanarayana, P.S. "Performance Evaluation of Vertical Handoff in Wireless Data Networks", in 4th International Conference on Wireless Communications, Networking and Mobile Computing, (WiCOM 08), pp. 1-4, Oct. 2008.

[14] D Martinez- Morales, V.P.rico, E.Steven. "Performance comparison between MADM algorithms for vertical handoff in $4 G$ networks", in 7th International Conference on Electri- cal Engineering Computing Science and Automatic Control, pp. 309-314, Septembre 2010.

[15] Escobar, L , et al, "Performance evaluation of Vertical Handoff Algorithms", in 6th IEEE Iternational Workshop on Performance and Managemenet of Wireless and Mobile Networks, p. 851-854, Oct 2010.

[16] Escobar, L , Navarro, A, Arteaga, A, Guerrero, F., and Salazar, C, "Vertical Handoff Algorithms A new approach for performance evaluation", in IEEE Globecom Worshop on Ubiquitous Computing and Networks, pp. 1724 - 1728, Dec. 2010.

[17] M. Lahby, C. Leghris. and A. Adib. "An Enhanced Evaluation Model For Vertical Handover Algorithm In Heterogeneous Networks", In International Journal of Computer Science Issues (IJCSI), Vol. 9, Issue 3, No 2, pp.254-259, May 2012.

[18] M. Gondara, S. Kadam. "Requirements of Vertical Handoff Mechanism in 4G Wireless Networks", In International Journal of Wireless and Mobile Networks (IJWMN), Vol. 3, No. 2, pp.18-27, April 2011.

[19] J. Lee, and S. Kim, “Using Analytic Network Process and Goal Programming for Interdependent Information System Project Selection ", Computers and Operation Research, Volume 27, Number 4, Page 367-382, April 2000.

[20] M. Lahby, C. Leghris. and A. Adib. "New multi access selection method based on Mahalanobis distance", Applied Mathematical Sciences, Vol. 6, no. 53-56, pp. 2745-2760, May 2012.

[21] G. Lampropoulos, K. Salkintzis and N. Passas, "Media Independent Handover for Seamless Service Provi-sion in Heterogeneous Networks", IEEE Communica-tions Magazine, Vol. 46, No. 1, pp. 64-71, 2008.

[22] “3GPP, QoS Concepts and Architecture” 2005, tS 22.107 (v 6.3.0). 